\title{
Determination of the Fluroxypyr Ester by HPLC with Internal Standard
}

\author{
Hua-Jing $\mathrm{ZHU}^{1,}$, , Ze-Li CHEN ${ }^{1, b}$ \\ ${ }^{1}$ Department of Biology and Environment Engineering of Tianjin Vocational Institute, Tianjin \\ 300410 ,P.R. China \\ azhj_czl@yahoo.cn, ${ }^{b}$ chenzeli7518@163.com
}

Keywords: High-performance liquid, Standard curves of internal standard method, Fluroxypyr esters.

\begin{abstract}
An HPLC method to determine fluroxypyr esters was established. Methods The SinoChrom ODS-BP $(5 \mu \mathrm{m}, 4.6 \mathrm{~mm} \times 200 \mathrm{~mm})$ column was used. The mobile phase was consisted of methanol-water(volume ratio $85: 15$ ). The flow rate was $1.0 \mathrm{~mL} / \mathrm{min}$. The column temperature was room temperature. The wavelength was $235 \mathrm{~nm}$. Results The o-nitroaniline was selected as internal standard for the determination. The linear range of fluroxypyr esters was $0.02 \sim 0.5 \mathrm{mg} / \mathrm{mL}, \mathrm{r}=0.9994$, the standard addition recovery was $99.5 \% \sim 100 \%$, and RSD was $0.2 \%(\mathrm{n}=6)$. Conclusion This method was proved to be accurate and reliable, so it could be applied to the quality control of measuring fluroxypyr esters.
\end{abstract}

\section{Introduction}

Fluroxypyr esters as a kind of the systemic conductive herbicide was developed by the Dow Chemical Company, which is widely used a variety of crops such as wheat, barley, maize, orchard [1 $\sim 2$ ]. The technology for detecting pesticide was limited to the chemical, colorimetric and bioassay method at initial and these methods had a poor performance in determination of related substances because the purity of the original pesticide was not high [3]. Gas chromatography was widely used for analysis of pesticides in the 1960's, thus the detection level of the pesticide was greatly improved. Since the 1980's, high-performance liquid chromatography (HPLC) began to be widely used in the analysis of the thermal instability and ionic pesticide and its metabolites. Because of its high separation efficiency, high detection efficiency, high analysis speed, and high sensitivity analysis, chromatography became broad and important means in the modern analysis field [4].

\section{Experiment}

\section{Instrument and Reagent}

High performance liquid chromatograph: Dalian Elite Analytical Instruments 230+ with P230+ pump, Uv 230+ detector and EC2000 Chromatography workstation; Ultrasonic cleaning machine: KQ3200B; The filter: GM-0.33 II diaphragm vacuum pump with $0.45 \mu \mathrm{m}$ membrane; Trace sampler (flat): $25 \mu \mathrm{L}$.

Methanol: chromatographic grade; Water: fresh distilled water; Fluroxypyr esters: known mass fraction 99\% or higher; Internal standard substance: picloram, triclopyr, 3, 6 - dichloro picolinic acid, and o-nitroaniline, known mass fraction $99 \%$ or higher.

Standard solution of fluroxypyr esters: the amount of fluroxypyr esters was accurately weighed, and was solved in methanol, so that the solution of $2.0 \mathrm{mg} \cdot \mathrm{mL}^{-1}$ was obtained.

Internal standard solution of o-nitroaniline: the amount of o-nitroaniline was accurately weighed, and was solved in methanol, so that the solution of $2.0 \mathrm{mg} \cdot \mathrm{mL}^{-1}$ was obtained. When it was used as internal standard solution, this solution was needed to dilute to $0.2 \mathrm{mg} \cdot \mathrm{mL}^{-1}$.

\section{Chromatographic Conditions}

The chromatographic column: SinoChrom ODS-BP $(5 \mu \mathrm{m}, 4.6 \mathrm{~mm} \times 200 \mathrm{~mm})$; Mobile Phase: methanol-water (volume ratio $85: 15$ ); The velocity: $1.0 \mathrm{~mL} / \mathrm{min}$; Column temperature: at room temperature; Wavelength: UV235mm; Sample quantity: $5 \mu \mathrm{L}$. 


\section{Results and Discussions}

\section{Selection of Internal Standard Substance}

Internal standard materials which are similar physical and chemical properties, such as triclopyr, o-nitroaniline, 3, 6 - dichloro picolinic acid, picloram, were optimized, the result is shown in figure 1:

A

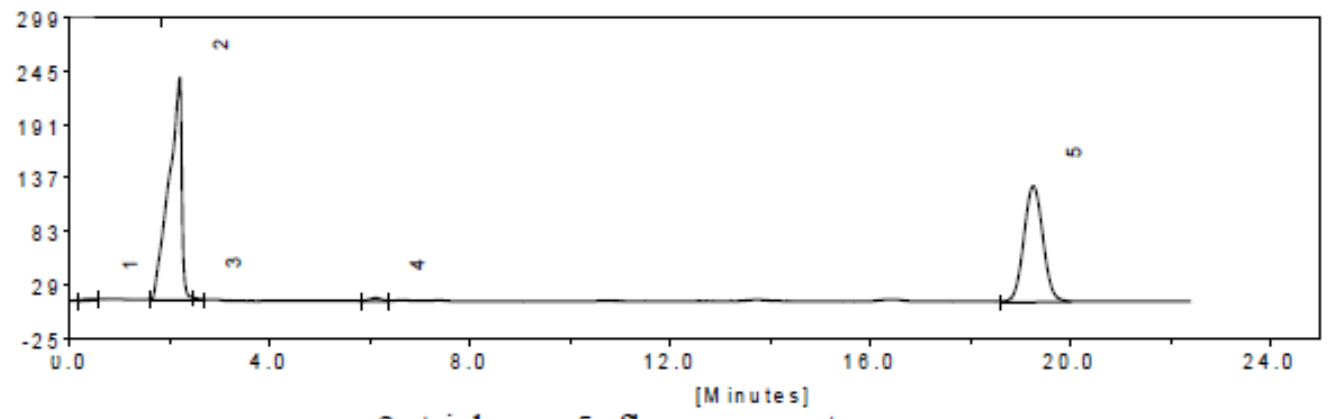

2- triclopyr 5-fluroxypyr esters

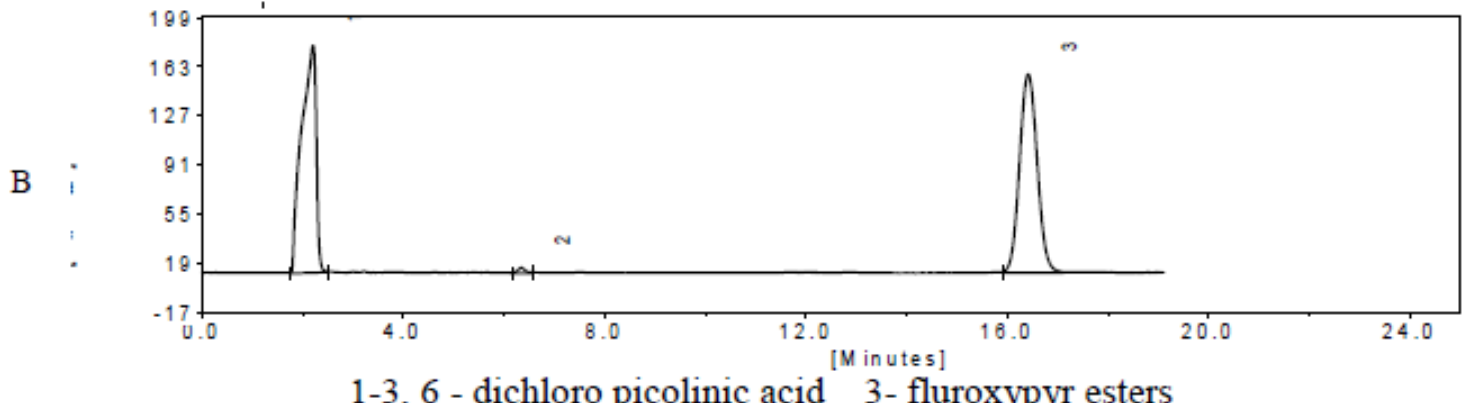

1-3, 6 - dichloro picolinic acid 3-fluroxypyr esters

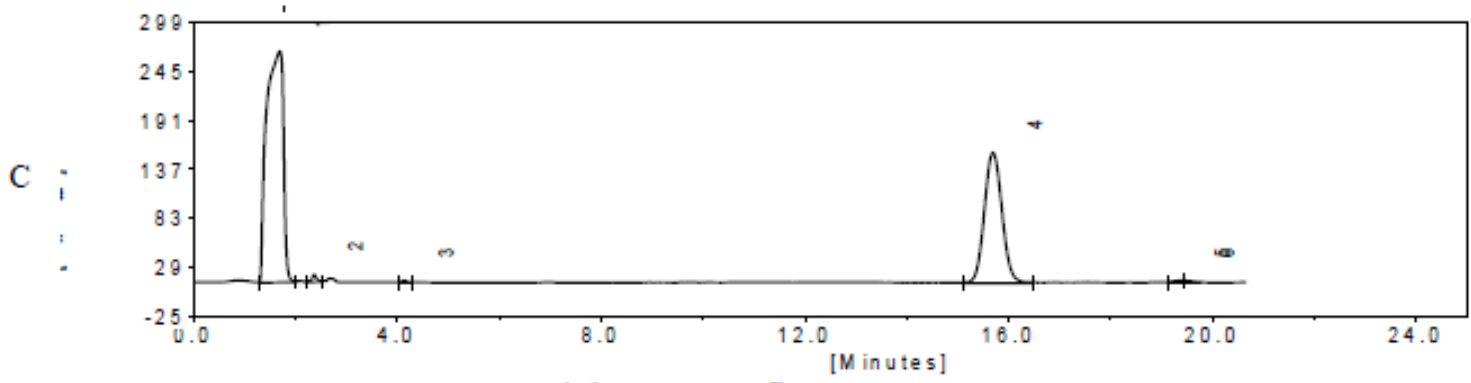

1- picloram 4- fluroxypyr esters

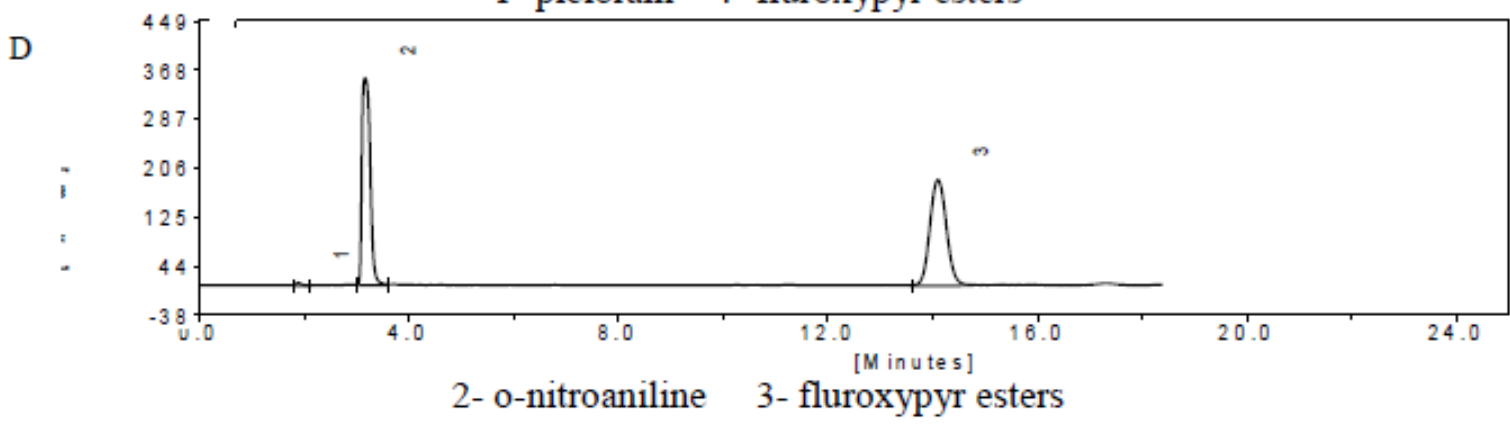

Fig.1 HPLC chromatograms

The experimental results show that the leading peak was found when the former three kinds of internal standard substance was added into the sample, and the shape of the peak was symmetrical and the separation was good when the sample was mixed with o-nitroaniline.

\section{Determination of Linear Equation}

Use a burette to accurately measure out a series of different volumes of the standard fluroxypyr esters solution into each of five $100 \mathrm{~mL}$ volumetric flasks, and add $25.0 \mathrm{~mL} 0.2 \mathrm{mg} \cdot \mathrm{mL}^{-1}$ of internal standard solution of o-nitroaniline to each flask, thus the concentrations of these standard sample solutions were $0.02,0.1,0.2,0.3,0.5 \mathrm{mg} \cdot \mathrm{mL}^{-1}$. Then in the same HPLC chromatographic conditions, 
inject $10.0 \mu \mathrm{L}$ of sample, respectively, and corresponding to the peak height and peak area can obtained from the chromatography workstation. The standard curve was constructed by plotting the ratio of fluroxypyr esters peak area to o-nitroaniline peak area versus mass concentration of fluroxypyr esters $\left(\mathrm{mg} \cdot \mathrm{mL}^{-1}\right)$, and regression equation can be for $\mathrm{y}=3.727 \mathrm{x}-0.026, \mathrm{r}=0.9994$. Results show that the linear relationship is good at the range of $0.02 \sim 0.5 \mathrm{mg} \cdot \mathrm{mL}^{-1}$.

\section{Determination of Standard Addition Recovery Rate}

An amount of known standard fluroxypyr esters was added to the blank sample, then these solutions were treated and determined according to the above analysis method, and the results are shown in table 1 . The recovery rate of this method was between $99.5 \% \sim 100.5$, the average recovery was $99.9 \%$, and RSD was $0.20 \%$.

Tab.1 The Standard Addition Recovery Rate of Fluroxypyr Esters

\begin{tabular}{|c|c|c|c|c|c|}
\hline Sample no. & $\begin{array}{l}\text { Amount of } \\
\text { Standard/g }\end{array}$ & $\begin{array}{l}\text { Measured } \\
\text { Results/g }\end{array}$ & $\begin{array}{c}\text { Recovery Rate } \\
1 \%\end{array}$ & $\begin{array}{c}\text { Average } \\
\text { Recovery } \\
1 \%\end{array}$ & $\mathrm{RSD} / \%$ \\
\hline 1 & 0.0234 & 0.0233 & 99.6 & \multirow{5}{*}{99.9} & \multirow{5}{*}{0.20} \\
\hline 2 & 0.0365 & 0.0367 & 100.5 & & \\
\hline 3 & 0.0458 & 0.0456 & 99.6 & & \\
\hline 4 & 0.0532 & 0.0533 & 100.2 & & \\
\hline 5 & 0.0613 & 0.0611 & 99.7 & & \\
\hline
\end{tabular}

\section{Precision Test of Analysis Methods}

Prepared a standard solution with a certain amount standard fluoride tobacco ester, then sampled 6 times repeatedly in the same HPLC chromatographic conditions, and every time took $10 \mu \mathrm{L}$. The results are shown in table 2.

Tab.2 The Determination Results of Precision for Fluroxypyr Esters

\begin{tabular}{|c|c|c|c|c|c|c|}
\hline No. & $\begin{array}{l}\text { Quality of the } \\
\text { Standard/g }\end{array}$ & $\begin{array}{l}\text { Quality of } \\
\text { the Internal } \\
\text { Standard /g }\end{array}$ & $\mathrm{A}_{\mathrm{s}} / \mathrm{A}_{\mathrm{is}}$ & $\begin{array}{c}\text { Mass } \\
\text { Fraction } \\
1 \%\end{array}$ & $\begin{array}{c}\text { Average } \\
\bar{x} / \%\end{array}$ & $\mathrm{RSD} / \%$ \\
\hline 1 & \multirow{6}{*}{0.0576} & \multirow{6}{*}{0.0564} & 0.79870 & 96.0 & \multirow{6}{*}{96.0} & \multirow{6}{*}{0.15} \\
\hline 2 & & & 0.80058 & 96.3 & & \\
\hline 3 & & & 0.79586 & 95.7 & & \\
\hline 4 & & & 0.80017 & 96.2 & & \\
\hline 5 & & & 0.79920 & 96.1 & & \\
\hline 6 & & & 0.79321 & 95.4 & & \\
\hline
\end{tabular}

\section{Repetitive Experiment}

Weighed 6 fluroxypyr ester samples (content> 95.0\%), then determined them in the same HPLC chromatographic conditions. The results are shown in table 3. 
Tab.3 The Determination Results of Repetitive Experiment

\begin{tabular}{c|c|c|c|c|c|c}
\hline No. & $\begin{array}{c}\text { Quality of } \\
\text { the } \\
\text { Sample } \\
/ \mathrm{g}\end{array}$ & $\begin{array}{c}\text { Quality of } \\
\text { the Internal } \\
\text { Standard } \\
/ \mathrm{g}\end{array}$ & $\mathrm{A}_{\mathrm{s}} / \mathrm{A}_{\mathrm{is}}$ & $\begin{array}{c}\text { Mass } \\
\text { Fraction } \\
/ \%\end{array}$ & $\begin{array}{c}\text { Average } \\
\overline{\boldsymbol{x}} / \%\end{array}$ & \multirow{2}{*}{ RSD/\% } \\
\hline 1 & 0.0556 & 0.0530 & 0.76834 & 95.8 & & \\
\hline 2 & 0.0563 & 0.0547 & 0.77895 & 95.9 & & \multirow{2}{*}{0.10} \\
\hline 3 & 0.0579 & 0.0546 & 0.80043 & 95.7 & & \\
\hline 5 & 0.0617 & 0.0550 & 0.85634 & 96.0 & & \\
\hline 6 & 0.0557 & 0.0546 & 0.76648 & 95.4 & & \\
\hline
\end{tabular}

\section{Determination of Samples}

Weighed three copies of fluroxypyr ester sample, and putted a certain amount of nitroaniline as internal standard substance, respectively, then made into $100 \mathrm{~mL}$ of methanol solution, determined five times for each sample solution with $10 \mu \mathrm{L}$. Calculated the content of fluroxypyr ester in the sample within the standard curve method, and figured out the RSD values of five content determinations, respectively.

Tab. 4 The Content of Fluroxypyr Esters in the Samples

\begin{tabular}{cccc}
\hline No. & Quality of the Sample/g & Quality of O-nitroaniline/g & RSD/\% \\
\hline 1 & 0.0230 & 0.0226 & 0.24 \\
2 & 0.0234 & 0.0229 & 0.18 \\
3 & 0.0231 & 0.0225 & 0.37 \\
\hline
\end{tabular}

\section{Conclusion}

Fluroxypyr ester is a kind of the systemic conductive herbicide which is used for treating the late of seeding stem. O-nitroaniline was selected as internal standard which is the similar properties and structure. It is favor to improve the accuracy of the method for measuring the content of fluroxypyr ester by using high performance liquid chromatography (HPLC) standard curves of internal standard method. This method is easy to operate, and the linear relationship between the $0.02 \sim 0.5 \mathrm{mg} / \mathrm{mL}$ is good, and the recovery rate is high, and the precision and repeatability is good, so this method can be used for quality control of fluorine tobacco ester herbicides.

\section{References}

[1] Liu Hualin, Huang Huacheng, Qiu Liqun, Wang Fangxian, Hu Guodong, Xie Ruifeng.Determination of Fluroxypyr Residues in Garlic and Corn by HPLC[J]. Chinese Journal of Chromatography, 2004,22(1): 92.

[2] Fang Chao, YI Hai-hua, NI Zhong. Determination of Fluroxypyr Residues in Vegetables by HPLC [J]. Guangzhou Chemical Industry, 2010, 38(12): 194 195.

[3] Institute of Plant Protection of Chinese Academy of Agricultural Sciences, Institute for the Control Agrochemicals of Agriculture and Fisheries, Bureau of Agricultural Means of Production of 
Ministry of Commerce. Analysis of pesticides (The third edition) [M]. Beijing: Chemical Industry Press, 1988:2.

[4] Zhang Baizhen, Ji Ying, Ye Jiming. Analysis of pesticides (The fourth edition) [M]. Beijing: Chemical Industry Press, 2005.

[5] Chen Daowen, Chen Rudong. Analysis of Fluroxypyr by High Performance Liquid Chromatography [J]. Agrochemicals, 1995,32(4):21 22.

[6] ZHU Hong, JIANG Yi-chun, LI Bo. Determination of New Herbicide of Fluroxypyr-dodecyl [J]. Agrochemicals, 2010,49(6):424 425.

[7] WANG Yue-jun, YIN Hai-yan. Analysis of Fluroxypyr by Reversed-phase High Performance Liquid Chromatography (HPLC) [J]. Hubei Plant Protection, 2005,(4):22 23.

[8] DUAN Jin-Sheng, PENG Mei, WANG Mei, etc. Residue Analysis of Fluroxypyr in Rice [J]. Agrochemicals, 2010,49(4):280 281. 